\title{
Satellite evidence for no change in terrestrial latent heat flux in the Three-River Headwaters region of China over the past three decades
}

\author{
Yunjun YaO ${ }^{1}$, Shaohua ZhaO ${ }^{2, *}$, Huawei Wan ${ }^{2}$, Yuhu Zhang ${ }^{3}$, \\ Bo Jiang ${ }^{1}$, Kun JiA ${ }^{1}$, Meng LiU ${ }^{4}$ and Jinhui Wu ${ }^{1}$ \\ ${ }^{1}$ State Key Laboratory of Remote Sensing Science, School of Geography, Beijing Normal University, \\ Beijing 100875, China. \\ ${ }^{2}$ Satellite Environment Center, Ministry of Environmental Protection, Beijing 100094, China. \\ ${ }^{3}$ College of Resource Environment and Tourism, Capital Normal University, Beijing 100048, China. \\ ${ }^{4}$ Institute of Geographic Sciences and Natural Resources Research, Chinese Academy of Sciences, \\ Beijing 100101, China. \\ *Corresponding author.e-mail: zshyytt@126.com
}

Terrestrial latent heat flux (LE) in the Three-River Headwaters region (TRHR) of China plays an essential role in quantifying the amount of water evaporation and carbon sink over the high altitude Tibetan Plateau (TP). Global warming is expected to accelerate terrestrial hydrological cycle and to increase evaporation. However, direct field observations are lacking in this region and the long-term variability in LE remains uncertain. In this study, we have revised a semi-empirical Penman LE algorithm based on ground eddy covariance (EC) observations from an alpine grass site and provided new satellitebased evidence to assess LE change in the TRHR during 1982-2010. Our results show that the average annual terrestrial LE in the TRHR is about $38.8 \mathrm{~W} / \mathrm{m}^{2}$ and there is no statistically significant change in annual LE from 1982 to 2010. We also found that during the same time period, terrestrial LE over the east region of the TRHR significantly decreased, on average, by $0.7 \mathrm{~W} / \mathrm{m}^{2}$ per decade, which was driven primarily by the surface incident solar radiation $\left(R_{s}\right)$ limitation, offsetting the increased LE over the west region of the TRHR caused by the increased precipitation $(P)$ and soil moisture $(S M)$.

\section{Introduction}

The terrestrial latent heat flux (LE) refers to the flux of heat from soil evaporation and vegetation transpiration and regulates climate change by altering the exchange of terrestrial energy, water and carbon with the atmosphere (Fisher et al. 2008; Trenberth et al. 2009; Liang et al. 2010; Yao et al. 2015). Especially in the Three-River Headwaters region (TRHR), which is a typical zone of the Tibetan Plateau (TP) of China and is most sensitive to climate change with the warming trend over past decades, LE is considered as a robust climatic predictor of water evaporation and carbon sink (Liu et al. 2008, 2014; Li et al. 2012; Zhang et al. 2013; Yao et al. 2016). Therefore, accurately estimating spatio-temporal variation in terrestrial LE over the TRHR is critical for understanding the hydrological cycle of the high altitude TP.

Global warming is expected to accelerate terrestrial hydrological cycle and to increase LE and evaporation in the TRHR (Liu et al. 2008; Trenberth et al. 2009). However, direct eddy covariance (EC) observations are lacking in the TRHR and hamper

Keywords. Terrestrial latent heat flux; Three-River Headwaters region; incident solar radiation; precipitation. 
to verify the expected changes in LE and evaporation. Although many satellite evapotranspiration (ET) products, such as the Moderate Resolution Imaging Spectroradiometer (MODIS) product (MOD16), are widely used to monitor the change in regional LE (Fisher et al. 2008; Jung et al. 2010; Mu et al. 2011; Yao et al. 2013), data are missing in the TRHR due to the existing gaps of MOD16 product. Many satellite-based LE algorithms (e.g., Budyko equation, energy residual method) are also used to assess the variation in LE in the high altitude TRHR (Liu et al. 2008). These studies show that an increasing trend in annual terrestrial LE occurs in the TRHR over the past two to three decades (Liu et al. 2008; Zhao et al. 2009). However, large uncertainties exist among these algorithms because recalibration of the algorithm parameters is generally neglected in previous studies for lack of needed data in the TRHR. As a result, little is accurately known about the spatio-temporal characterization of the response of the LE in the TRHR to hydro-climate on large spatial scales over the past three decades.

Recently, Wang et al. (2010) proposed an operational semi-empirical Penman (SEMI-Penman) algorithm to monitor global terrestrial LE on decadal scales based on a Penman equation and up-scaling local EC observations. One limitation of the SEMIPenman algorithm is that the land cover types of the training EC observation sites do not include alpine grass, which makes LE estimates uncertain in the TRHR. Because the main land cover type is grassland and alpine meadow accounting for more than $65 \%$ of the total area of the TRHR, EC observed data for alpine meadow sites in Qinghai Province, China, can be considered as references to revise the SEMI-Penman algorithm for LE estimation in the TRHR. In this study, we assessed the variation in terrestrial LE in the TRHR and its attributions over the past three decades with an alternative revised SEMI-Penman algorithm.

\section{Materials and methods}

\subsection{Study area}

The TRHR, the source area of the Yellow, Yangtze and Lantsang rivers, is located in the southern region of Qinghai Province, China, with the latitude ranging from $31.65^{\circ}$ to $36.20^{\circ} \mathrm{N}$ and longitude being $89.75^{\circ}$ to $102.38^{\circ} \mathrm{E}$ (figure 1). The TRHR is known as 'Chinese water tower' because the topography of the most parts of the study area is a plateau region with average $4000 \mathrm{~m}$ above sea level. The annual mean temperature is below $10^{\circ} \mathrm{C}$ and annual mean rainfall of this region is about $513 \mathrm{~mm}$. More than $80 \%$ of the annual rainfall occurs during the summer season from June to August. Alpine meadow, widely distributed at $3500-4000 \mathrm{~m}$, is the main ecosystem type in the TRHR and is dominated by Kobresia spp (Xu et al. 2008a; Fan et al. 2010). Figure 1 shows the International GeosphereBiosphere Programme (IGBP) land cover types from MOD12 products that characterise the study region.

\subsection{Data}

Ground-measured flux data of eddy covariance (EC) from 1 January, 2002, to 30 December, 2004, at Haibei flux tower site adjacent to the THTR were collected from Asiaflux website (http://www. asiaflux.net/). The corresponding flux data including LE, sensible heat flux $(H)$, surface incident solar radiation $\left(R_{s}\right)$, surface net radiation flux $\left(R_{n}\right)$, soil heat flux $(G)$, precipitation $(P)$, relative humidity $(R H)$, wind speed ( $W S)$, vapour pressure $(e)$ and air temperature $\left(T_{a}\right)$, averaged over $30 \mathrm{~min}$, were used in this study. Post-processing of the EC data steps includes de-spiking, sonic temperature, and coordinate corrections ( $\mathrm{Xu}$ et al. 2008b). We also used the method developed by Twine et al. (2000) to correct the LE values at the Haibei site due to the energy imbalance problem of the EC method. Because the ecosystem type of the Haibei site is also alpine meadow and both the TRHR and Haibei site belong to the same plateau continental climate, the EC data can be used to revise the SEMI-Penman algorithm for estimating LE in the TRHR.

To drive the SEMI-Penman algorithm, we used the bimonthly NOAA/AVHRR normalised difference vegetation index (NDVI) product provided by the Global Inventory Modeling and Mapping Studies (GIMMS) group at NASA GSFC at a spatial resolution of $8 \mathrm{~km}$ during 1982-2010 (Tucker et al. 2005). The daily NDVI values were temporally interpolated from the bimonthly averages using linear interpolation. To estimate regional LE, we used the gridded meteorological datasets for daily $T_{a}, P, R_{s}, R H, W S$ and $e$ for the period $1982-2010$, on a $0.1^{\circ} \times 0.1^{\circ}$ grid. These datasets were developed by Data Assimilation and Modeling Center for Tibetan Multi-spheres, Institute of Tibetan Plateau Research and Chinese Academy of Sciences (CAS) and provided by Environmental \& Ecological Science Data Center for West China (Yang et al. 2010; Chen et al. 2011; He and Yang 2011). Land surface soil moisture (SM) was derived from the Advanced Microwave Scanning Radiometer-Earth Observing System (AMSR-E) sensor on the Aqua satellite for the period 20032010 on a 0.25 degree spatial resolution provided by the National Snow and Ice Data Center (NSIDC) (Lobl 2001). To better correspond with the gridded meteorological datasets, the GIMMS-NDVI and 


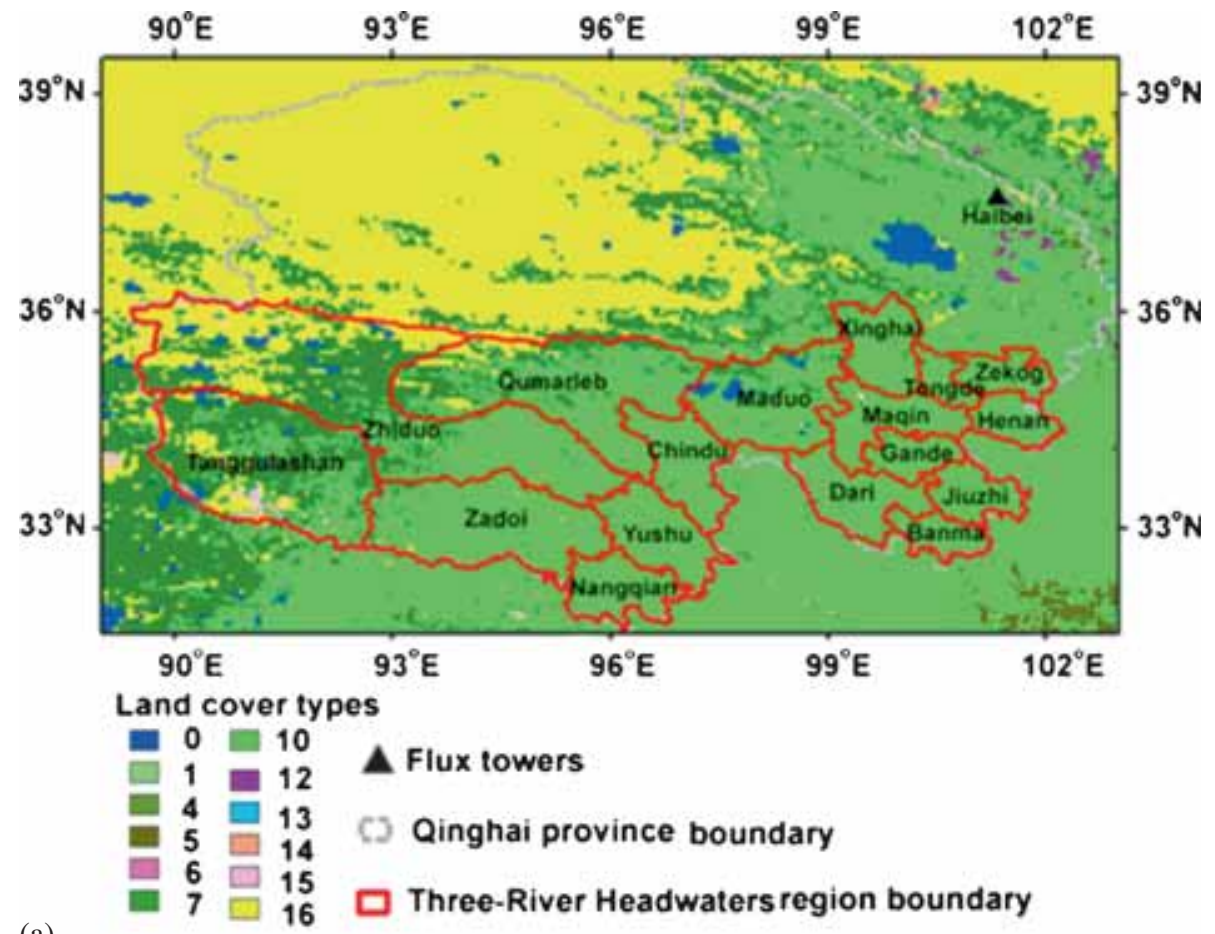

(a)

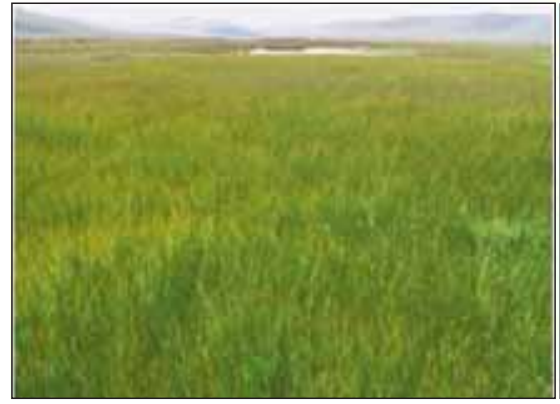

(b)

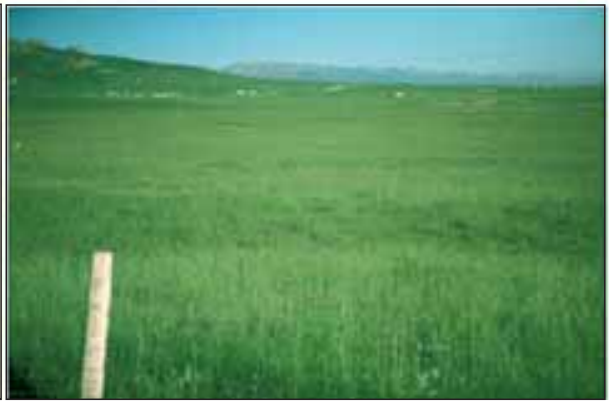

(c)

Figure 1. (a) Sketch map of the Three-River Headwaters region in the Qinghai-Tibetan Plateau (TP), China. IGBP land cover types are shown: 0: water body; 1 : evergreen needleleaf forest; 2: evergreen broadleaf forest; 3: deciduous needleleaf forest; 4: deciduous broadleaf forest; 5: mixed forest; 6: closed shrubland; 7: open shrubland; 8: woody savanna; 9: savanna; 10: grassland; 11: permanent wetland; 12: crop land; 13: urban/build up; 14: crop land/natural vegetation mosaic; 15: snow/ice; and 16: barren lands. (b) Photo of alpine meadow for the Haibei site (photo source from Chinaflux: http:// www.chinaflux.org/gczd/index.aspx?nodeid=86). (c) Photo of alpine meadow for the TRHR (photo source from Upper and Middle Yellow River Bureau: http://www.hhsb.gov.cn/news/9634).

AMSR-E $S M$ data were interpolated into a resolution of $0.1^{\circ} \times 0.1^{\circ}$ using bilinear interpolation method.

\subsection{Methods}

Considering that the semi-empirical Penman LE (SEMI-Penman) algorithm, developed by Wang et al. (2010), includes the effects of WS on LE and can be used for detecting regional LE on decadal scales, its coefficients can be revised to assess the variation in LE in the TRHR and the algorithm can be written as:

$$
L E_{e s}=a_{1}\left(L E_{E}+L E_{A}\right)+a_{2}\left(L E_{E}+L E_{A}\right)^{2},
$$

$$
\begin{aligned}
L E_{E}= & \frac{\Delta}{\Delta+\gamma} R_{s}\left[a_{3}+a_{4} N D V I\right. \\
& \left.+(1-R H)\left(a_{5}+a_{6} N D V I\right)\right]
\end{aligned}
$$

and

$$
\begin{aligned}
L E_{A}= & \frac{\gamma}{\Delta+\gamma} W S\left[a_{7}+(1-R H)\right. \\
& \left.\times\left(a_{8}+a_{9} N D V I\right)\right] V P D,
\end{aligned}
$$

where $L E_{e s}$ is the estimated LE. $a_{1}=0.819, a_{2}=$ $0.0017, a_{3}=0.476, a_{4}=0.284, a_{5}=-0.654$, $a_{6}=0.264, a_{7}=3.06, a_{8}=-3.86$ and $a_{9}=3.64$. $\Delta$ is the slope of the saturated vapour pressure curve $\left(\mathrm{KP}_{\mathrm{a}} /{ }^{\circ} \mathrm{C}\right), \gamma$ is the psychrometric constant $\left(\mathrm{KP}_{\mathrm{a}} /{ }^{\circ} \mathrm{C}\right), V P D$ is the vapour pressure deficit 
$\left(\mathrm{KP}_{\mathrm{a}}\right)$. Considering that all empirical coefficients were calibrated using EC data at 64 globally distributed sites and these sites include a variety of land cover: grass, rangeland, pastures, crop fields, forests and mixed land cover, and considering that their locations also differ greatly from each other, we find these sufficiently representative for the purpose of estimating LE in the TRHR. In this study, we used a simple linear regression equation to recalibrate these empirical coefficients based on the statistical relationships between the estimated LE using the equation (1) and ground-measured LE at Haibei site and it can be expressed as:

$$
L E_{c}=k \times L E_{e s},
$$

where $L E_{c}$ is the corrected LE using the EC data at the Haibei site and $k$ is the linear regression coefficient. Since there are 3 years (2002-2004) of data available at Haibei flux tower site, we selected a three-fold cross-validation method to evaluate the performance of equation (4). We divided the samples into three groups with roughly equal numbers and each group having one year of data. Then equation (4) for each of the three groups was independently validated using the samples of the remaining two groups.

For water body, the Priestley-Taylor (PT) equation was then used to estimate LE of water evaporation (Priestley and Taylor 1972).

$$
\mathrm{LE}=\alpha \frac{\Delta}{\Delta+\gamma}\left(R_{n}-G\right)
$$

where $\alpha$ is the PT coefficient, which refers to evaporation arising from the atmospheric $V P D$ and was set to 1.26 in this study.

\section{Results and discussion}

\subsection{Evaluation of algorithm performance in estimating LE}

The comparison of the measured and estimated daily LE at the Haibei flux tower site using equation (1) demonstrates that the original SEMIPenman algorithm tends to underestimate LE
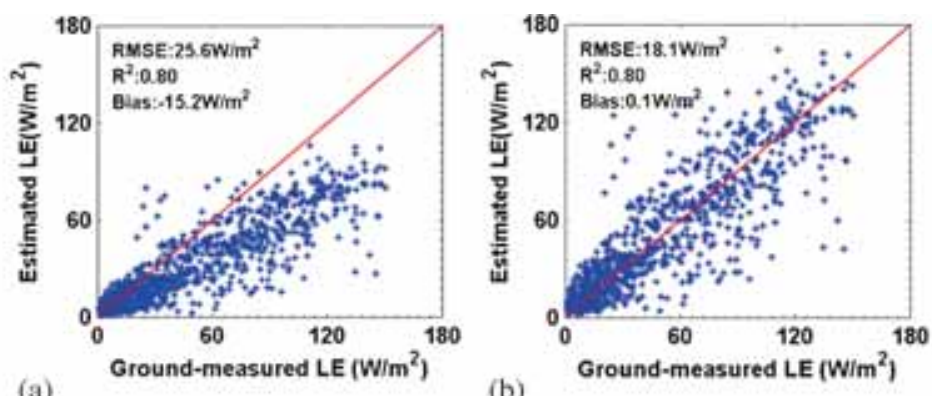

(a)

(b)

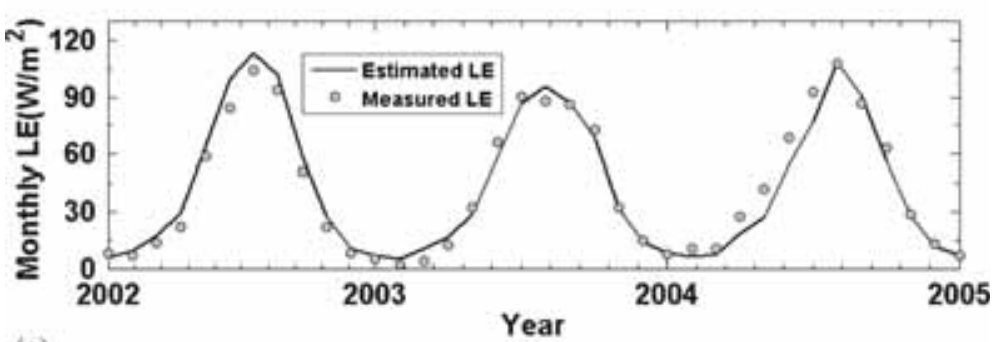

(c)

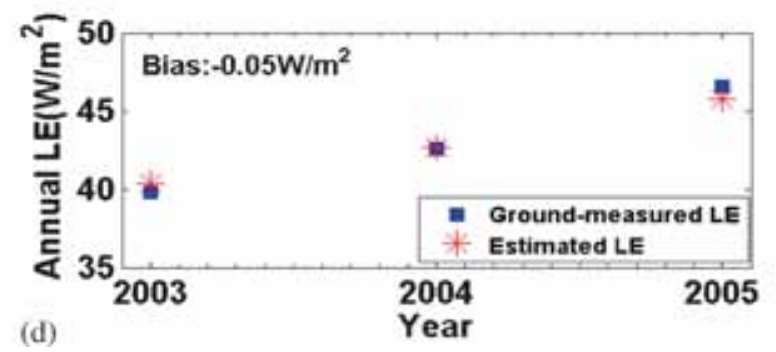

Figure 2. (a) Comparison of the daily LE observations for Haibei site and the corresponding estimated LE using the equation (1); (b) cross-validation of the daily LE observations for Haibei site and the corresponding estimated LE using the equation (4); (c) comparison of the monthly LE observations for Haibei site and the corresponding estimated LE using the equation (4); and (d) comparison of the annual LE observations for Haibei site and the corresponding estimated LE using the equation (4). 
significantly for alpine meadow site (figure 2a). On average, the daily LE is estimated with a root mean square error (RMSE) of $25.6 \mathrm{~W} / \mathrm{m}^{2}$ and a bias of $-15.2 \mathrm{~W} / \mathrm{m}^{2}$. The squared correlation coefficient $\left(R^{2}\right)$ is $0.80(p<0.01)$.

To improve the performance of the SEMIPenman algorithm for estimating LE in the TRHR dominated with mainly alpine meadow, we used the equation (4) and EC data at the Haibei site to revise the SEMI-Penman algorithm. Figure 2(b) shows the comparison between the daily LE observations and LE estimates using the equation (4) based on a three-fold cross-validation method for alpine meadow site. One can notice that the regression based on $2 / 3$ of samples of the datasets successfully estimates the other $1 / 3$ of the data and the SEMI-Penman algorithm has improved the accuracy of LE estimates for alpine meadow site by decreasing RMSE by $7 \mathrm{~W} / \mathrm{m}^{2}$ compared to the original algorithm.

Based on all meteorological variables and groundobserved EC data of Haibei site, equation (4) can be written as:

$$
L E_{c}=1.548 \times L E_{e s} .
$$

Figure 2(c) presents a time series for monthly LE measurements and predictions at Haibei site using the equation (6). It is clear that equation (6) yields reasonable seasonal LE variations that are close to the ground-measured values. Figure $2(\mathrm{~d})$ shows that the equation (6) offers the highest simulation accuracy for annual LE with a bias of -0.05 $\mathrm{W} / \mathrm{m}^{2}$, indicating the revised algorithm captures the observed seasonal and inter-annual variations in LE.

Because the original SEMI-Penman algorithm includes the variety of land cover (e.g., pastures, crop fields, forests) and the revised algorithm also considers the effects of the alpine meadow, we find the revised algorithm is sufficiently representative for the purpose of estimating terrestrial LE in the TRHR. In this study, the observed EC data is considered as accurately 'true' value to revise the LE algorithm, but approximately $20-50 \mathrm{~W} / \mathrm{m}^{2}$ of the EC measured errors and approximately 0.8 of energy closure ratio $\left((L E+H) /\left(R_{n}-G\right)\right)$ will also lead to large uncertainties when estimating LE in the TRHR (Wilson et al. 2002; Foken 2008; Mahrt 2010). The spatial resolutions of the AVHRR-NDVI and meteorological gridded datasets are all more than $8 \mathrm{~km}$ while the EC sites have a footprint of approximately $200 \mathrm{~m}$ (McCabe and Wood 2006; Yao et al. 2014a). This spatial mismatch between the flux tower site footprints and gridded footprints will also cause large uncertainties for LE estimation. In addition, error propagation through calculations, including EC energy closure correction, threshold filtering, gap filling and temporal interpolation, will amplify the errors for LE estimation (Wang and Dickinson 2012; Shi and Liang 2014; Yao et al. 2014b).

\subsection{Spatial patterns of terrestrial LE}

Based on equation (6) driven by AVHRR-NDVI and gridded meteorological data, we produced regional LE product in the TRHR with a spatial resolution of 0.1 degree during 1982-2010. The spatial distribution of the annual LE is consistent with the previous studies (Liu et al. 2008; Zhao et al. 2009). As shown in figure 3, the highest annual LE occurs in the south-east humid regions, whereas the north-west arid regions of the TRHR have the lowest annual LE due to the surface moisture limitations and their short growth seasons.

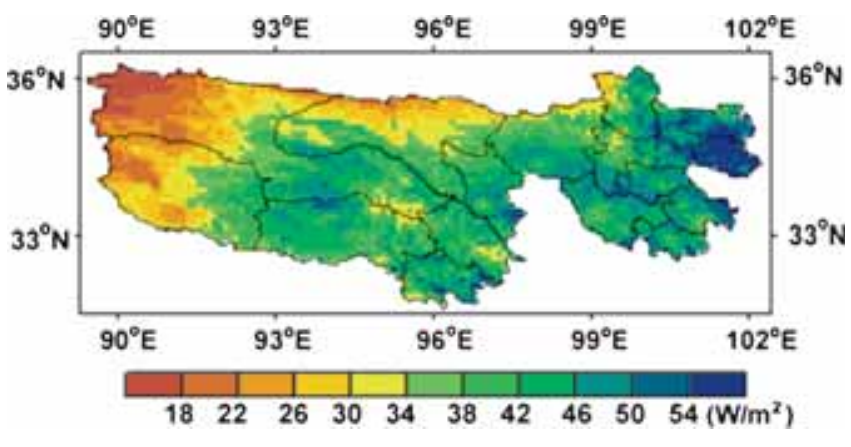

Figure 3. Spatial patterns of mean annual terrestrial LE in the TRHR from 1982 to 2010.

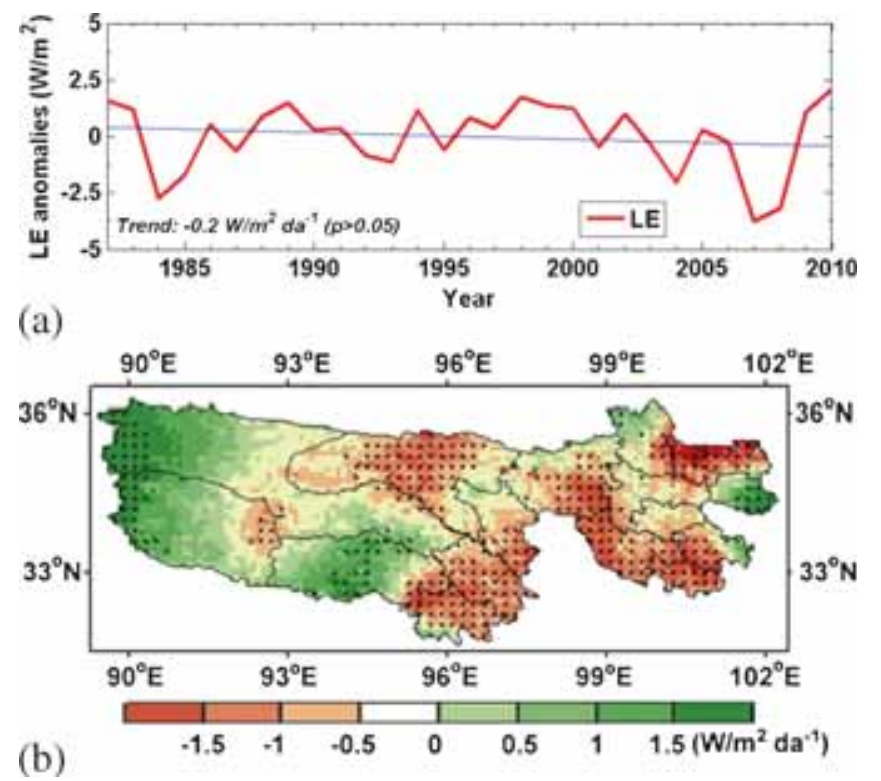

Figure 4. (a) Inter-annual variability of the terrestrial LE anomaly and (b) spatial distribution of the terrestrial LE trends in the TRHR. The dashed lines refer to the linear trends for 1982-2010. The black solid dots refer to grids with $95 \%$ confidence. 
The mean annual land LE value for the TRHR during $1982-2010$ is approximately $38.8 \mathrm{~W} / \mathrm{m}^{2}$ $\left(35-40.8 \mathrm{~W} / \mathrm{m}^{2}\right)$, which is higher than the values of other studies (Liu et al. 2008; Zhang et al. 2010). For example, Liu et al. (2008) reported the mean annual ET between 1980 and 2000 in the TRHR was $217.8 \mathrm{~mm}$ (or $16.9 \mathrm{~W} / \mathrm{m}^{2}$ ) based on the water and heat balance (WHB) equation. Zhang et al. (2010) used the Penman-Monteith (PM) algorithm to estimate ET during 2006-2007 in the TRHR and found the mean annual ET for steppe was 275.4 $\mathrm{mm}$ (or $21.4 \mathrm{~W} / \mathrm{m}^{2}$ ). The primary cause of this discrepancy in estimating annual LE may be a deficiency of observations modifying the parameters of the previous WHB and PM methods.

\subsection{Variation in terrestrial LE over the past three decades}

Our terrestrial LE estimate of the TRHR, derived from remote sensing and gridded meteorological observations, demonstrates that the linear trend in terrestrial LE has been found to be slightly negative, at about $-0.2 \mathrm{~W} / \mathrm{m}^{2}$ per decade for $1982-$ 2010 , and the trend is not statistically significant $(p>0.05)$ (figure 4$)$. The negative LE trend with no significant confidence is opposite to the previous findings due to the expected accelerated hydrological cycle associated with rising temperature (Liu et al. 2008; Zhang et al. 2010). Indeed, for the same time period, terrestrial LE over the west region (west of $95^{\circ} \mathrm{E}$ ) of the TRHR slightly increased on average by $0.5 \mathrm{~W} / \mathrm{m}^{2}$ per decade. However, there
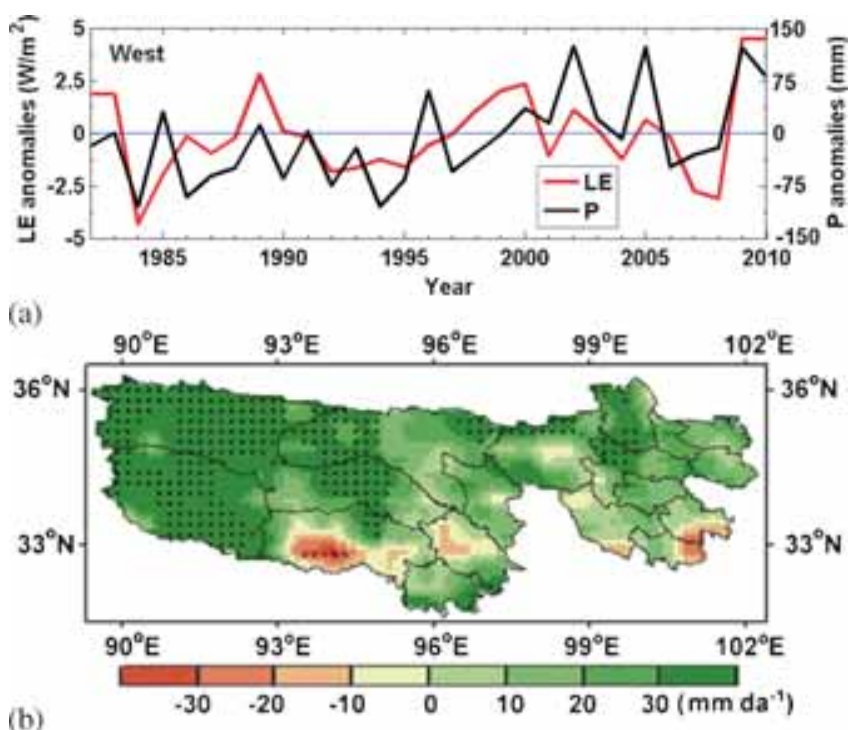

(b)

Figure 5. (a) Inter-annual variability of the terrestrial LE and $P$ anomaly in the west region of the TRHR. (b) Spatial distribution of the terrestrial $P$ trends for 1982-2010 in the TRHR. The black solid dots refer to grids with $95 \%$ confidence. is no significant correlation between inter-annual variability in $T_{a}$ and $\mathrm{LE}$ variability. We wondered whether variability in $P$ could be the reason for the rising of LE trend over the west region (west of $126^{\circ} \mathrm{E}$ ) of the TRHR, which belongs to the semiarid and arid regions. Figure 5 shows the strong coherence between 1982-2010 LE trends derived from satellite data, and trends in the independent gridded $P$ over the west region of the TRHR in which surface moisture is expected to affect LE. Overall, the correlation coefficient between the annual anomalies of LE and $P$ over the west region of the TRHR was $0.60(p<0.05)$. In theory, $S M$ trends are more consistent with LE trends because $S M$ is a better proxy for moisture supply of LE and inter-annual variability in $S M$ correlates well with $P$ variability (Jung et al. 2010; Zeng et al. 2014) (figure 6). In arid and semi-arid regions, scarce $P$ leads to dry soil and LE becomes restricted by $S M$ and $P$. Yet, the relatively short time period (2003-2010) of AMSR-E $S M$ data fails to detect the variation in $S M$ over the past three decades.

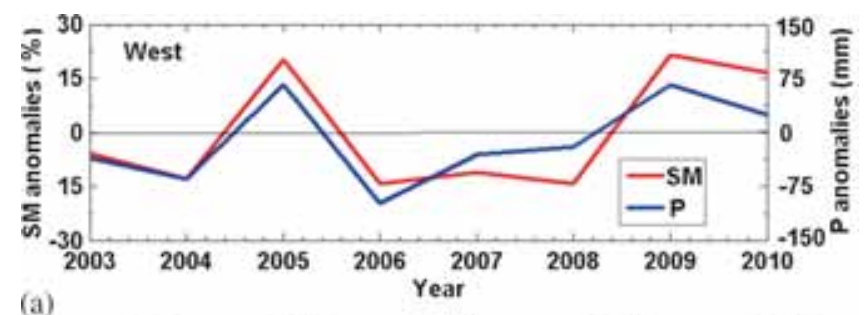

(a)

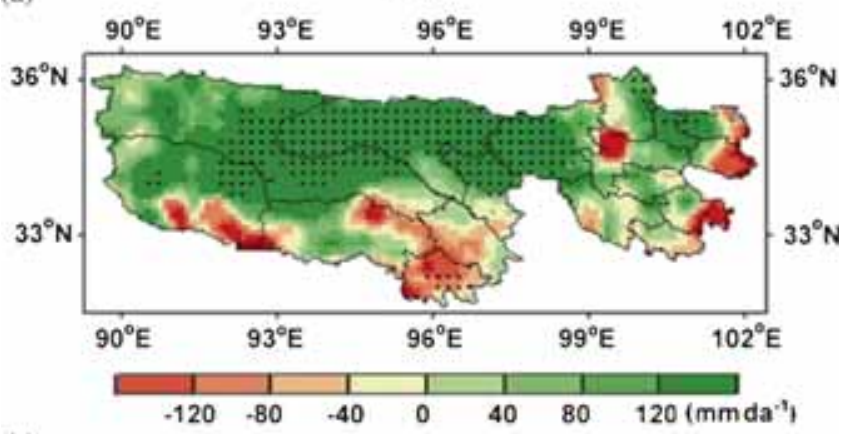

(b)

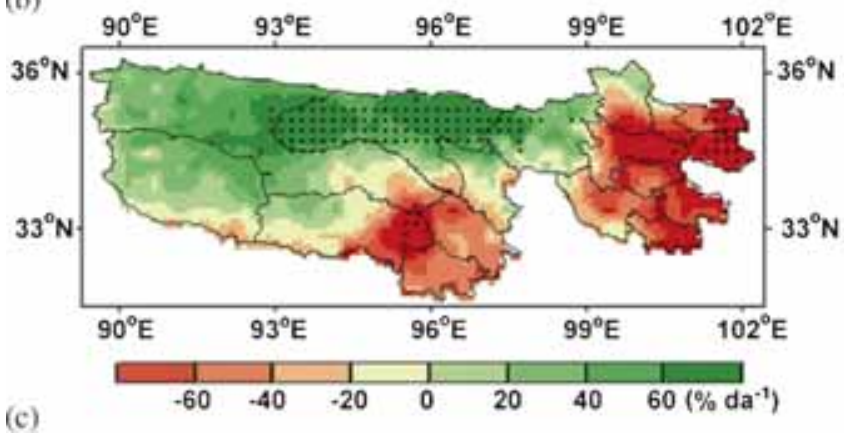

Figure 6. (a) Inter-annual variability of the terrestrial $P$ and AMSR-E SM anomaly in the west region of the TRHR. Spatial distribution of the terrestrial (b) $P$ and (c) AMSR-E trends for 2003-2010 in the TRHR. The black solid dots refer to grids with $95 \%$ confidence. 
The pattern of increasing LE matched by a $P$ rising illustrates that increasing $P$ is the main mechanism, contributing to the rising LE trend over the west region of the TRHR during 1982-2010 (Jung et al. 2010; Yao et al. 2014b).

However, in the eastern humid regions (east of $95^{\circ} \mathrm{E}$ ) of the TRHR, terrestrial LE significantly decreased on average by $0.7 \mathrm{~W} / \mathrm{m}^{2}$ per decade from 1982 to 2010; which was consistent with the variation in $R_{s}$ (figure 7 ), offsetting the increased LE over the west region of the TRHR caused by the increased $P$. Statistically significant $(p<0.05)$ positive correlations between annual $\mathrm{LE}$ and $R_{s}$ were found in $78 \%$ of the east region of the TRHR. The strong spatial consistency of the patterns in the estimated LE and $R_{s}$ trends indicates that decreasing $R_{s}$ in the eastern humid regions of the TRHR is the primary contributor to the variation in terrestrial LE because the east region is an energy-limited environment. Other mechanisms that could be responsible for a decreasing LE seem to be less important because of the weak correlations between the variation in LE and other climate factors. Many scientists reported that decreasing $R_{s}$ trend may be caused by the steadily increasing aerosol optical depth (AOD) in the eastern and central Tibetan Plateau (TP) or in the surrounding regions over the past decades, especially after 1980 (Liang and Xia 2005; You et al. 2013). However, Tang et al. (2011) supported the view that the importance of cloud changes in altering $R_{s}$ may be comparable to that of the aerosol changes. The detailed causes of the variation in $R_{s}$ still remain
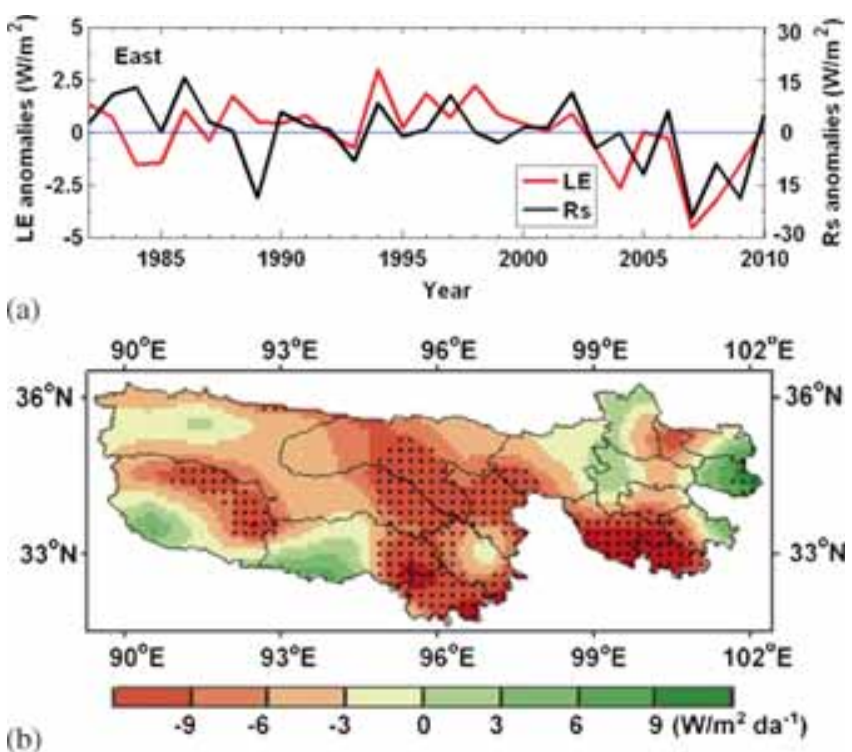

(b)

Figure 7. (a) Inter-annual variability of the terrestrial LE and $R_{s}$ anomaly in the east region of the TRHR. (b) Spatial distribution of the terrestrial $R_{s}$ trends for $1982-2010$ in the TRHR. The black solid dots refer to grids with $95 \%$ confidence. uncertain. Based on our results, we argue that variations in both $P$ and $R_{s}$, rather than $T_{a}$, are the most climate variables to alter the trend in LE in the TRHR. Because the significance of these trends is limited by the relatively short time period of the satellite record, it is difficult to assess whether this is normal climate oscillation or a climate-change signal associated with carbon sink and regional atmosphere feedback.

\section{Conclusions}

We estimated the spatio-temporal change in terrestrial LE in the TRHR from 1982 to 2010 using a semi-empirical Penman LE algorithm based on ground eddy covariance (EC) observations from an alpine grass site in this study. The mean annual land LE value for the TRHR during 1982-2010 is approximately $38.8 \mathrm{~W} / \mathrm{m}^{2}\left(35-40.8 \mathrm{~W} / \mathrm{m}^{2}\right)$, which is higher than the values of other studies due to the deficiency of observations modifying the parameters of the previous WHB and PM methods. In contrast to the concurrent increasing trends in LE in the TRHR due to the global warming, we have provided satellite evidence that there is no statistically significant change in annual LE from 1982 to 2010. However, we also found that terrestrial LE over the east region of the TRHR significantly decreased on average by $0.7 \mathrm{~W} / \mathrm{m}^{2}$ per decade due to the decreasing $R_{s}$, offsetting the increased LE over the west region of the TRHR due to the rising $P$.

There are a few problems that deserve further study. Our revised semi-empirical Penman LE algorithm was modified by EC data of an alpine grass site, which ignores the revision for other land cover types and suffers from a 'space for time' substitution hypothesis. The effects of rising atmospheric $\mathrm{CO}_{2}$ concentrations were also ignored in our algorithm, which causes additional uncertainties. In the future, we will focus on the impacts of the land use change and increasing $\mathrm{CO}_{2}$ on terrestrial $\mathrm{LE}$ in the TRHR over the past several decades.

\section{Acknowledgements}

We gratefully acknowledge Dr Kun Yang, from Institute of Tibetan Plateau Research, Chinese Academy of Sciences, for providing gridded meteorological data. The forcing dataset used in this study was developed by Data Assimilation and Modeling Center for Tibetan Multi-spheres, Institute of Tibetan Plateau Research, Chinese Academy of Sciences and this dataset is provided by the 'Environmental \& Ecological Science Data Center for West China, National Natural Science 
Foundation of China' (http://westdc.westgis.ac.cn). This work was partially supported by the Natural Science Fund of China (41201331 \& 41331173), the High Resolution Earth Observation Systems of National Science and Technology Major Projects (No. 05-Y30B02-9001-13/15-9), the Science \& Technology Innovation Fund for Remote Sensing Young Talents of NRSCC (KJHX2015372) and the National High Technology Research and Development Program of China (2013AA122801).

\section{References}

Chen Y, Yang K, He J, Qin J, Shi J, Du J and He Q 2011 Improving land surface temperature modeling for dry land of China; J. Geophys. Res. 116 D20104.

Fan J, Shao Q, Liu J, Wang J, Harris W, Chen Z, Zhong H, $\mathrm{Xu}$ X and Liu R 2010 Assessment of effects of climate change and grazing activity on grassland yield in the Three Rivers Headwaters Region of QinghaiTibet Plateau; China Environ. Monit. Assess. 170 571-584.

Fisher J, Tu K and Baldocchi D 2008 Global estimates of the land atmosphere water flux based on monthly AVHRR and ISLSCP-II data, validated at 16 FLUXNET sites; Remote Sens. Environ. 112 901-919.

Foken T 2008 The energy balance closure problem: An overview; Ecol. Appl. 18 1351-1367.

He J and Yang K 2011 China Meteorological Forcing Dataset; Cold and Arid Regions Science Data Center, Lanzhou, China, doi: 10.3972/westdc.002.2014.db.

Jung M et al. 2010 Recent decline in the global land evapotranspiration trend due to limited moisture supply; Nature 467 951-954.

Liang F and Xia X 2005 Long-term trends in solar radiation and the associated climatic factors over China for 19612000; Ann. Geophys. 23 2425-2432.

Liang S, Wang K, Zhang X and Wild M 2010 Review on estimation of land surface radiation and energy budgets from ground measurement, remote sensing and model simulations; IEEE J. Sel. Top. Appl. Earth Obs. Remote Sens. $3225-240$.

Li H, Liu G and Fu B 2012 Estimation of regional evapotranspiration in alpine area and its response to land use change: A case study in Three-River Headwaters region of Qinghai-Tibet Plateau China; Chinese Geogr. Sci. 22 437-449.

Liu J, Xu X and Shao Q 2008 The spatial and temporal characteristics of grassland degradation in the Three-River Headwaters region in Qinghai Province; J. Geogr. Sci. 18 259-273.

Liu X, Zhu X, Zhu W, Pan Y, Zhang C and Zhang D 2014 Changes in spring phenology in the Three-Rivers Headwater region from 1999 to 2013; Remote Sens. 6 91309144.

Lobl E 2001 Joint Advanced Microwave Scanning Radiometer (AMSR) Science Team meeting; Earth Observer 13 3-9.

Mahrt L 2010 Computing turbulent fluxes near the surface: Needed improvements; Agric. For. Meteorol. 150 501-509.

McCabe M and Wood E 2006 Scale influences on the remote estimation of evapotranspiration using multiple satellite sensors; Remote Sens. Environ. 105 271-285.

$\mathrm{Mu}$ Q, Zhao M and Running S 2011 Improvements to a MODIS global terrestrial evapotranspiration algorithm; Remote Sens. Environ. 115 1781-1800.
Priestley C and Taylor R 1972 On the assessment of surface heat flux and evaporation using large-scale parameters; Mon. Weather Rev. 100 81-92.

Shi Q and Liang S 2014 Surface sensible and latent heat fluxes over the Tibetan Plateau from ground measurements, reanalysis, and satellite data; Atmos. Chem. Phys. 14 5659-5677.

Tang W, Yang K, Qin J, Cheng C and He J 2011 Solar radiation trend across China in recent decades: A revisit with quality-controlled data; Atmos. Chem. Phys. 11 393-406.

Trenberth K, Fasullo J and Kiehl J 2009 Earth's global energy budget; Bull. Am. Meteorol. Soc. 90 311-323.

Tucker C, Pinzon J E, Brown M E, Slayback D A, Pak E W, Mahoney R, Vermote E F and El Saleous N 2005 An extended AVHRR $8 \mathrm{~km}$ NDVI dataset compatible with MODIS and SPOT vegetation NDVI data; Int. J. Remote Sens. 26 4485-4498.

Twine $\mathrm{T}$ E, Kustas W P, Norman J M, Cook D R, Houser P R, Meyers T P, Prueger J H, Starks P J and Wesely M L 2000 Correcting eddy-covariance flux underestimates over a grassland; Agric. For. Meteorol. 103 279-300.

Wang K and Dickinson R 2012 A review of global terrestrial evapotranspiration: Observation, modeling, climatology, and climatic variability; Rev. Geophys. 50 RG2005.

Wang K, Dickinson R, Wild M and Liang S 2010 Evidence for decadal variation in global terrestrial evapotranspiration between 1982 and 2002: 1. Model development; J. Geophys. Res. 115 D20112.

Wilson K, Aubinet M, Baldocchi D, Goldstein A and Berbigier P 2002 Energy balance closure at FLUXNET sites; Agric. For. Meteorol. 113 223-243.

$\mathrm{Xu} \mathrm{X,} \mathrm{Liu} \mathrm{J,} \mathrm{Shao} \mathrm{Q} \mathrm{and} \mathrm{Fan} \mathrm{J} \mathrm{2008a} \mathrm{The} \mathrm{dynamic}$ changes of ecosystem spatial pattern and structure in the Three River Headwaters Region in Qinghai Province during recent 30 years; Geogr. Res. 27 829-838 (in Chinese).

Xu Z, Liu S, Gong L, Wang J and Li X 2008b A study on the data processing and quality assessment of the eddy covariance system; Adv. Earth Planet. Sci. 23 357-370 (in Chinese).

Yang K, He J, Tang W, Qin J and Cheng C 2010 On downward shortwave and longwave radiations over high altitude regions: Observation and modeling in the Tibetan Plateau; Agric. For. Meteorol. 150 38-46.

Yao Y et al. 2013 MODIS-driven estimation of terrestrial latent heat flux in China based on a modified Priestley-Taylor algorithm; Agric. For. Meteorol. 171172 187-202.

Yao Y et al. 2014a Bayesian multimodel estimation of global terrestrial latent heat flux from eddy covariance, meteorological, and satellite observations; J. Geophys. Res. 119 4521-4545.

Yao Y, Liang S, Xie X, Cheng J, Jia K, Li Y and Liu R 2014b Estimation of the terrestrial water budget over northern China by merging multiple datasets; J. Hydrol. 519 50-68.

Yao Y et al. 2015 A satellite-based hybrid algorithm to determine the Priestley-Taylor parameter for global terrestrial latent heat flux estimation across multiple biomes; Remote Sens. Environ. 165 216-233.

Yao Y et al. 2016 Assessment and simulation of global terrestrial latent heat flux by synthesis of CMIP5 climate models and surface eddy covariance observations; Agric. For. Meteorol. 223 151-167.

You Q, Sanchez-Lorenzo A, Wild M, Folini D, Fraedrich K, Ren G and Kang S 2013 Decadal variation of surface 
solar radiation in the Tibetan Plateau from observations, reanalysis and model simulations; Clim. Dyn. 40 20732086.

Zeng Z, Wang T, Zhou F, Ciais P, Mao J, Shi X and Piao S 2014 A worldwide analysis of spatiotemporal changes in water balance-based evapotranspiration from 1982 to 2009; J. Geophys. Res. 119 1186-1202.

Zhang Y et al. 2010 Correlation between evapotranspiration and climate factors in warm steppe in source region of
Yangtze, Yellow and Yalu Tsangpo Rivers; J. Desert Res. 30 363-368 (in Chinese).

Zhang G, Zhang Y, Dong J and Xiao X 2013 Green-up dates in the Tibetan Plateau have continuously advanced from 1982 to 2011; Proc. Natl. Acad. Sci. USA 110 4309-4314.

Zhao J, Jiang Q, Chen F and Wang K 2009 RS based evaporation estimation of Three River sources in Qinghai-Tibet Plateau and its response to lakes and wetlands; J. Jilin Univ. (Earth Sci. Ed.) 39 507-513 (in Chinese).

MS received 8 October 2015; revised 30 May 2016; accepted 31 May 2016

Corresponding editor: Pradeep Kumar Thapliyal 